\title{
Testing Hypotheses for the Success of Different Conservation Strategies
}

\author{
JEREMY S. BROOKS, ${ }^{*}$ MARGARET A. FRANZEN, ${ }^{*}$ CHRISTOPHER M. HOLMES,${ }^{*} \dagger$ \\ MARK N. GROTE, $\neq$ AND MONIQUE BORGERHOFF MULDER $\AA^{*} \oint^{* *}$ \\ *Graduate Group in Ecology, University of California at Davis, Davis, CA 95616, U.S.A. \\ †Institute for the Conservation of Tropical Biology (ICTE), Department of Anthropology, SUNY Stony Brook, New York, \\ NY 11794, U.S.A. \\ ‡Department of Anthropology, University of California at Davis, Davis, CA 95616, U.S.A. \\ $\S$ Center for Population Biology, University of California at Davis, Davis, CA 95616, U.S.A.
}

\begin{abstract}
Evaluations of the success of different conservation strategies are still in their infancy. We used four different measures of project outcomes-ecological, economic, attitudinal, and behavioral-to test bypotheses derived from the assumptions that underlie contemporary conservation solutions. Our bypotheses concerned the effects of natural resource utilization, market integration, decentralization, and community bomogeneity on project success. We reviewed the conservation and development literature and used a specific protocol to extract and code the information in a sample of papers. Although our results are by no means conclusive and suffer from the paucity of high-quality data and independent monitoring (80\% of the original sample of 124 projects provided inadequate information for use in this study), they show that permitted use of natural resources, market access, and greater community involvement in the conservation project are all important factors for a successful outcome. Without better monitoring schemes in place, it is still impossible to provide a systematic evaluation of how different strategies are best suited to different conservation challenges.
\end{abstract}

Keywords: conservation monitoring, decentralization, integrated conservation and development, market access, protectionism

Probando Hipótesis para el Éxito de Diferentes Estrategias de Conservación

Resumen: Las evaluaciones del éxito de diferentes estrategias de conservación aun están en su infancia. Utilizamos cuatro medidas diferentes de resultados de proyectos-ecológicos, económicos, de actitud y conductuales-para probar bipótesis derivadas de las suposiciones que subyacen en las soluciones de conservación contemporáneas. Nuestras hipótesis se relacionaron con los efectos de la utilización de recursos naturales, la integración de mercados, la descentralización y la beterogeneidad de la comunidad sobre el éxito del proyecto. Revisamos la literatura de conservación y desarrollo y utilizamos un protocolo específico para extraer y codificar la información en una muestra de artículos. Nuestros resultados, aunque no son concluyentes y sufren la escasez de datos de alta calidad y el monitoreo independiente (80\% de la muestra original de 124 proyectos proporcionó información inadecuada para este estudio), muestran que el uso autorizado de recursos naturales, el acceso al mercado y una mayor participación de la comunidad en el proyecto de conservación son factores importantes para un resultado exitoso. Sin mejores esquemas de monitoreo in situ todavía es imposible proporcionar una evaluación sistemática de cómo las diferentes estrategias están mejor adaptadas a los diferentes retos de la conservación.

Palabras Clave: acceso al mercado, conservación y desarrollo integrados, descentralización, monitoreo de la conservación, proteccionismo

\footnotetext{
**Address correspondence to M. Borgerboff Mulder, email mborgerboffmulder@ucdavis.edu Paper submitted May 18, 2005; revised manuscript accepted November 7, 2005.
} 


\section{Introduction}

The critique of protectionism that emerged in the 1980s has spawned an array of conservation strategies that promote, to various degrees, the welfare and cooperation of the people living in and around protected areas. Such strategies provide a mix of conservation and development objectives (Borgerhoff Mulder \& Coppolillo 2005) and employ a range of tactics, such as providing appropriate development opportunities (Abbot et al. 2001), emphasizing local community involvement (Western 1994; Getz et al. 1999), adopting shared management (Murphree 1994), ensuring local autonomy (Muller 2003), guaranteeing rights to harvest (Fearnside 1989; Browder 1992), promoting knowledge (Jacobson \& McDuff 1998), awarding cash compensation (Ferraro \& Kiss 2002), and encouraging tourism (Honey 1999).

Despite the prominence of such strategies linking conservation and development as primary conservation tools, and strong arguments for and against their effectiveness (Wells et al. 1992; Barrett \& Arcese 1995; Oates 1999; McShane \& Wells 2004), there have been few quantitative comparative evaluations of their successes and failures. There are, however, exceptions. Bruner et al. (2001) studied vegetational changes associated with protectionism (and its absence), and Salafsky et al. (2001) identified design features of enterprise strategies for community-based conservation projects that produce successful outcomes. In a more recent study, Struhsaker et al. (2005) examined correlates of conservation success in Africa's forests and considered, among other factors, the presence of integrated conservation and development projects (ICDPs).

Following the call of Sutherland et al. (2004) and Saterson et al. (2004) for independent evaluation of the reasons why different strategies succeed and fail, we used data from 28 projects that purportedly link conservation and development to test quantitatively some of the assumptions that underlie current conservation strategies. Although specific projects become known for specific strategies (e.g., ecotourism in the Galapagos or community-based conservation in southern Africa), in practice more than one strategy is used in any one project (Borgerhoff Mulder \& Coppolillo 2005). Accordingly, we focused not on specific strategies per se but on the assumptions underlying the strategies currently embraced by many conservation organizations. In particular, we considered the utilization-protection continuum, market integration, decentralization, and community homogeneity. Although our results provide some support for the intuitions driving the conservation and development approach, existing data are insufficient to make substantive claims about the efficacy of the conservation and development paradigm as a whole or about specific characteristics that may result in success for a particular project. Our study should, however, stimulate further, more rigorous comparative analyses as more data become available.

\section{Measures of Success}

Much of the debate among those concerned with conservation strategy and policy results from an interest in different outcomes. Social scientists focus on a community's economic well-being and empowerment, whereas natural scientists pay closer attention to biological impacts of resource use. Consider, for example, the debate over extractive reserves. For Schwartzman et al. (2000a), a wellconserved forest is one that sequesters carbon, does not burn, has stable hydrology and soils, and provides a productive home for forest-living peoples. For others (e.g., Redford 1992), a well-conserved forest is one that harbors ecologically functional populations of all species within the ecosystem, thereby providing for the conservation of the full set of species, genes, and ecological relationships. Unsurprisingly, such authors disagree over the viability of extractive reserves (Schwarzman et al. 2000b), a disagreement that illustrates the different perspectives of social versus natural scientists (Naughton-Treves et al. 2005).

Recognizing these multiple perspectives, we included in our analysis four outcome measures as criteria for evaluating the success or failure of conservation and development projects: ecological, economic, attitudinal, and behavioral. We define ecological success in terms of the consequences for one or a set of species (or habitats) designated as targets of the conservation project. Economic success refers to the consequences for material welfare of the communities affected. Underlying these economic and ecological outcomes are the attitudes and behaviors of local residents: attitudinal success is defined in terms of the views of local residents to the goals of the conservation project and behavioral success refers to changes in behavior likely to reduce threats to natural resources. Although changes in attitudes are an important consequence of a conservation project, positive attitudes do not ensure ecological success and are not necessarily correlated with economic success (Holmes 2003). Furthermore, if positive attitudes do not translate into conservation-friendly actions, then they are strictly irrelevant to ecological outcomes (Adams \& Hulme 2001; Holmes 2003). Ideally, all four outcomes should be considered together when studying conservation and development projects, with the recognition that there may be a temporal aspect to their emergence; for example, positive behavioral outcomes might occur prior to the observation of positive ecological outcomes.

\section{Hypotheses}

We tested predictions underlying the logic of the integrated conservation and development framework representing the view from the social sciences. The four hypotheses are stated in their most naïve form with the understanding that there are nuances, complications, and alternative predictions for each. These complexities are raised in the discussion, specifically with respect to the 
suitability of different strategies in different contexts. We labeled our four hypotheses utilization/protection, market integration, decentralization, and community homogeneity.

First, we hypothesized that greater levels of utilization generate support for, and compliance with, conservation initiatives. Although high levels of protection contribute to ecological success (Caro et al. 1998; Bruner 2001), this may not be a general pattern and may compromise economic, attitudinal, and behavioral success. This is particularly likely when protected areas have been established without local consultation or when their management is underfunded (Balmford \& Whitten 2003). In such cases, local communities may resent losing access to (or receiving insufficient compensation for) the resources they used previously and accordingly increase illegal offtake (e.g., Lindsay 1987). The general assumption underlying our prediction is that because income generation is linked to sustainable utilization of natural resources, local communities will recognize the importance of regulating resource use, and their attitudes and behaviors toward conservation will change accordingly. Opening up areas to human use, whether as buffer zones or extractive reserves, may increase support for conservation while minimizing human impacts, yielding the prediction that projects emphasizing utilization will show increased economic, attitudinal, behavioral, and ultimately ecological success. This somewhat naïve prediction assumes that utilization generates income, is sustainable, and does not adversely affect other species (see Discussion).

Second, we hypothesized that where conservation projects facilitate increased market integration, there is greater local support for resource management and conservation. Integration of local communities into larger regional or national markets entails many changes (e.g., alternative sources of income, access to substitute subsistence goods, new markets for local products, changed material aspirations), each with distinct potential conservation outcomes. The dynamic we focused on is developed most fully by Godoy et al. (1995; see also Hulme \& Murphree 1999): increased external income offered by markets can decrease dependence on local forests either through substitution of commercial alternatives or by devaluing forest goods in comparison with income earned through wage labor. Both pathways decrease the incentive to extract resources for sale in the market. The prediction then is that greater market integration will show increased economic, attitudinal, behavioral, and ultimately ecological success, although we realize that negative effects are a possibility (see Discussion).

Our third hypothesis concerned decentralization: with greater local input in conservation decisions and greater community control over programs, the attitudes and behaviors of residents change in a positive way. Some support for this view comes from a study of local enterprise initiatives linked to conservation projects in Southeast
Asia (Salafsky \& Wollenberg 2000). The idea that empowering local communities should make them more responsive to conservation initiatives lies at the heart of community-based conservation programs (Wyckoff-Baird et al. 2000; Ribot 2004). The benefits of decentralization derive from the assumption that local bodies will be more responsive to conservation initiatives than national governments. Again multiple lines of logic are implied. First, local communities are thought to have greater knowledge of the intricate dynamics of their natural resource base than outsiders and to have more incentive to sustain it over time. They are also presumed to have lower discount rates than a commercial intruder. The prediction then is that decentralization, defined here primarily in terms of the extent to which project design and implementation is devolved to local communities, is associated with increased economic, attitudinal, behavioral, and ultimately ecological success. As we acknowledge in the discussion, successful decentralization depends on both the presence of functioning institutions within the community and on the socioeconomic and political conditions prior to decentralization.

Our final hypothesis concerned community homogeneity: the more homogeneous a community, the more successful the project is in all aspects. Cultural homogeneity is thought to facilitate the functioning of community institutions for resource management by increasing trust between community members and thus reducing transaction costs (Ostrom 1990) and has been identified as an important factor in success in the Zimbabwean CAMPFIRE program (Barrow \& Murphree 2001). Compared with a more heterogeneous community, a culturally homogeneous community is expected to cooperate more often and more efficiently to solve collective action problems, such as common-pool resource management issues arising in and around project areas. Situations in which heterogeneity might boost rather than impede collective action are outlined in the Discussion.

\section{Methods}

\section{Sample}

The impetus for this project originated from case studies analyzed for Borgerhoff Mulder and Coppolillo (2005). We reviewed the bibliographies of these case studies and the bibliographies of ICDPs by Flintan (2000) and Brown (2002) for additional papers. In addition, we conducted Web-based searches with ISI Web of Knowledge, Anthropology Plus, Biblioline, and JSTOR electronic databases. We searched for the terms ICDP, community based conservation, and conservation and development in each database. This search produced 124 relevant papers.

To be included in the final sample (see Supplementary Material below), a paper had to (1) have been peerreviewed, (2) include monitoring, and (3) cover two or 
more of the four outcome measures (ecological, economic, attitudinal, and behavioral). Reviews of conservation and development projects in edited volumes were not included. Papers giving only an overview of the project or a descriptive explanation of implementation and outcomes were not used. Papers examining the impacts of a national park on local communities in the absence of a conservation and development project were excluded. Fifty percent of the articles were excluded, because there was no monitoring or evaluation or only one outcome measure was reported, and $22 \%$ were excluded because there was no project associated with the protected area. We excluded another $9 \%$, because the article reviewed either CAMPFIRE or ADMADE. For such projects with multiple locations that could count as distinct cases (Hulme \& Murphree 2001) only one site was used, following the criteria of selection outlined above. Our final sample size was 28 projects from 24 papers (one paper reviewed three projects, whereas two other papers reviewed two projects each).

\section{Coding}

We created variables to describe a project's local environment, protected area, community (or communities) affected, threats to the local environment, and monitoring information related to the success of the project. We collected 60 pieces of information for each paper. Only those directly relevant to the major hypotheses are discussed here.

Two researchers (J.S.B. and M.A.F.) coded each paper separately. When coders disagreed, they discussed their decisions and then chose the most appropriate code. Coders based their decisions only on the information presented. To pretest coding categories and test intercoder reliability, the coding protocol was applied to the review of ICDPs in Indonesia done by Wells et al. (1999). This publication was not included because it was not peerreviewed and it did not contain a sufficient number of monitored outcome variables.

\section{Predictor Variables}

For the utilization/protection hypothesis (Table 1), we used two predictor variables: the protected area IUCN ranking (IUCN) and amount of resource use permitted in the project area (use). We supplemented the former with the latter measure because in some contexts, the IUCN ranking is a poor indicator of actual usage patterns (Naughton-Treves et al. 2005). To test the market integration hypothesis, we used four predictor variables, each dealing with a different aspect of market incursion (sell, purchase, labor) and the scale of the threat resulting from resource extraction (threat). To test the decentralization hypothesis, we used three variables: implementation (level of the organization responsible for implementing the project), decision (level of community involvement in a project's day-to-day running once it was implemented), and benefits (targeted beneficiaries of the project). The community homogeneity hypothesis had only one predictor variable, population (whether or not the source of local population growth is from local residents or from immigration). Few papers included appropriate ethnographic, cultural and social data on the population(s) in the project area, making a more precise measure of this variable difficult to obtain. All variables consisted of categories ordered (Table 1) so that positive associations between predictor and outcome measures provided evidence consistent with the four hypotheses.

\section{Analysis}

We examined two-dimensional contingency tables of predictors and outcomes, and used Monte Carlo and false discovery rate (FDR) methods (Benjamini \& Hochberg 1995) to determine statistical significance. We used the Goodman-Kruskal gamma statistic (Goodman \& Kruskal 1954; Agresti 1990) to summarize the association between a predictor and response and as a test statistic for Monte Carlo significance tests. Gamma, which lies in the interval $[-1,1]$, is the difference between the sample frequencies of concordant and discordant pairs of observations when the ordinations of both predictor and outcome are considered. Unlike other measures of ordinal association (e.g., Agresti 1990), gamma does not require that numerical "scores" be assigned by the observer (often arbitrarily) to the levels of a variable. Hypothesis tests based on gamma have known drawbacks (e.g., Cohen \& Sackrowitz 1992), but they are balanced by the natural interpretability of gamma for the present data. Because of the way the variable categories were ordered (Table 1), we interpreted a value of gamma relatively close to 1 as evidence in favor of the hypothesis under consideration.

With 10 predictors and 4 outcomes, there were 40 twodimensional tables to be tested; and correlations within the sets of predictors and outcomes were likely to be present. These considerations and the small sample size made it necessary to mitigate problems of multiple testing. We adjusted significance levels from the 40 hypothesis tests with $q$ values (Storey 2002; reviewed in Roback \& Askins 2005) to obtain approximate control of the FDR, defined as the expected proportion of false-positive tests among tests called significant. Storey (2002) describes algorithms which take ordered significance levels ( $p$ values) from multiple hypothesis tests, returning a corresponding sequence of $q$ values connected to the FDR for the tests. Approximate control of the FDR is achieved by setting a threshold for the $q$ values; for example, calling the tests having $q$ values $\leq 0.05$ significant implies that, of those tests, only about $5 \%$ are expected to be truly null-hypothesis cases. 
Table 1. Variables used in analysis of conservation and development projects and descriptions of variable categories. ${ }^{a}$

Hypotheses

and variables

Explanations and categories

Utlization/protection

$\mathrm{IUCN}^{b}$

use $^{b}$

IUCN ranking of the protected area from most protected to least (http://www.iucn.org/themes/wcpa/ppa/ protectedareas.htm), three categories: strict nature reserve, national park, other (national monument, habitat/species management area, protected landscape, managed resource area)

amount of resource use permitted in or around the protected area from least use to most, three categories: ecotourism; ICDP emphasizing substitution, compensation, or some combination of the two; and ICDP in which enhancement is emphasized in an addition to any other goal

(Compensation refers to development projects, substitution to alternatives that remove pressure from the threatened resource, and enhancement to improving the market for the resource to increase value and control (for definitions, see Abbot et al. [2001] and Brandon [1997].)

Market integration sell

how involved the local community is in market sales, scored from least involvement to most, three categories: minimal, moderate, and large

purchase

labor

threat $^{b}$

Decentralization implementation $^{b}$

decision

how involved the local community is in market purchases, scored from least involvement to most, three categories: minimal, moderate, and large

how involved the local community is in wage labor, scored from least involvement to most, three categories: minimal, moderate, and large

threats to the protected area, three noted for each project, including commercial poaching, subsistence poaching, fuelwood poaching, grazing, subsistence agriculture, commercial agriculture, tourism, commercial industry, commerical timber; coded by motivation (subsistence, cash) and severity (minimal, moderate, large): subsistence/minimal, moderate, or large, and cash/minimal, 1; cash/moderate, 2; cash/large, 3. Sum of three threats is total score (1-9) and is condensed into four categories: $1-2,3,4-5,6-9$

administrative level of the organization responsible for implementing the project, scored from least community involvement to most, two categories: national, international, or some combination and regional, community, household, individual

level of community involvement with respect to day-to-day decision making, scored from least community involvement to most (Berkes et al. 1991), three categories:

no community control, locals informed of regulations, and local concerns addressed;

some community involvement, advisory partnership, involvement of management boards, use of local knowledge and field assistants; and complete community control, power to community or joint management

benefits $^{b}$

targeted beneficiaries-up to two beneficiaries noted for each project, scored from least community benefit to most, three categories: no community, benefits directed to either the regional level or above (regional, national, international); community/other, benefits are directed in part to the community level or below (household, individual); community, benefits are directed exclusively to the community level or below (community, household, individual)

Homogeneity population

Outcomes ecological economic

attitudinal

behavioral source of population growth in the area, scored from least homogeneous to most, two categories: immigrant and local

project outcomes with regard to ecological goals, three categories: failure, limited success, and success project outcomes with regard to the economic impact on the local people, three categories: failure, limited success, and success

project outcomes with respect to local attitudes toward conservation, three categories: failure, limited success, and success

project outcomes with respect to decreasing the occurrence of illegal or targeted activities, three categories: failure, limited success, and success

\footnotetext{
${ }^{a}$ The coding protocol, data, and R language scripts used in data analysis are available (see Supplementary Material). Most variables contain missing values. Abbreviations: IUCN, World Conservation Union; ICDP, Integrated Conservation and Development Project.

${ }^{b}$ Variables were analyzed using fewer ordered categories than in the original protocol. Because of the small sample size, variables with several (e.g., greater than five) categories in the original protocol tended to have few observations in each category. Adjacent categories were combined for such variables when appropriate given the natural ordering of the categories.
}

We obtained a Monte Carlo $p$ value and associated $q$ value for each test of ordinal association as follows. For an observed table, 5000 random tables (having the same row and column sums as the observed table) were gen- erated under the null hypothesis of independence of predictor and outcome. These tables were generated with the function "r2dtable" in the statistical software R ( R Development Core Team 2004, version 2.0.1). For each 
random table, the Goodman-Kruskal gamma statistic was calculated and stored. Because the alternative hypothesis was directional (i.e., positive association between predictor and outcome), we calculated a "one-sided" $p$ value as equal to the observed gamma, divided by 5000 . The $p$ values obtained in this way from the 40 observed tables were then supplied to the $q$ value software (available at bttp://faculty.wasbington.edu/ jstorey/), which calculates $q$ values for the Monte Carlo significance tests. We used the bootstrap option in $q$ value and allowed the tuning parameter lambda to range in $\left[0, \mathrm{p}^{*}\right]$, where $\mathrm{p}^{*}$ was the 75 th percentile of the Monte Carlo $p$ values.

\section{Results}

There was a notable tendency overall for these gamma statistics to lie above zero, broadly confirming the positive associations underlying the four hypotheses (Fig. 1). Sample sizes for the tables ranged from $n=7$ (for purchase $\times$ ecological success) to $n=25$ (for threat $\times$ economic the number of random gamma statistics greater than or

success); thus, the statistical power to detect association varied widely. We called eight of the tests significant. Control of the FDR by $q$ values then implies that of these eight tests, about one $(0.1 \times 8)$ is expected to be a truly null case.

The results (Fig. 1) show evidence for greater attitudinal success among projects with more purchasing (purchase) and selling (sell) opportunities; greater behavioral success among projects with more community involvement in the establishment (implementation) and day-today running (decision) of a project; greater ecological success among projects in which the community was involved in day-to-day activities (decision); and greater economic success among projects that make fewer restrictions on the use of the protected area (IUCN) and provide more opportunities for selling natural products (sell) and more community input into day-to-day management (decision). There was therefore some support for three of the four hypotheses, with decentralization, market integration, and utilization of resources predicting, respectively, four, three, and one of our original measures of success.

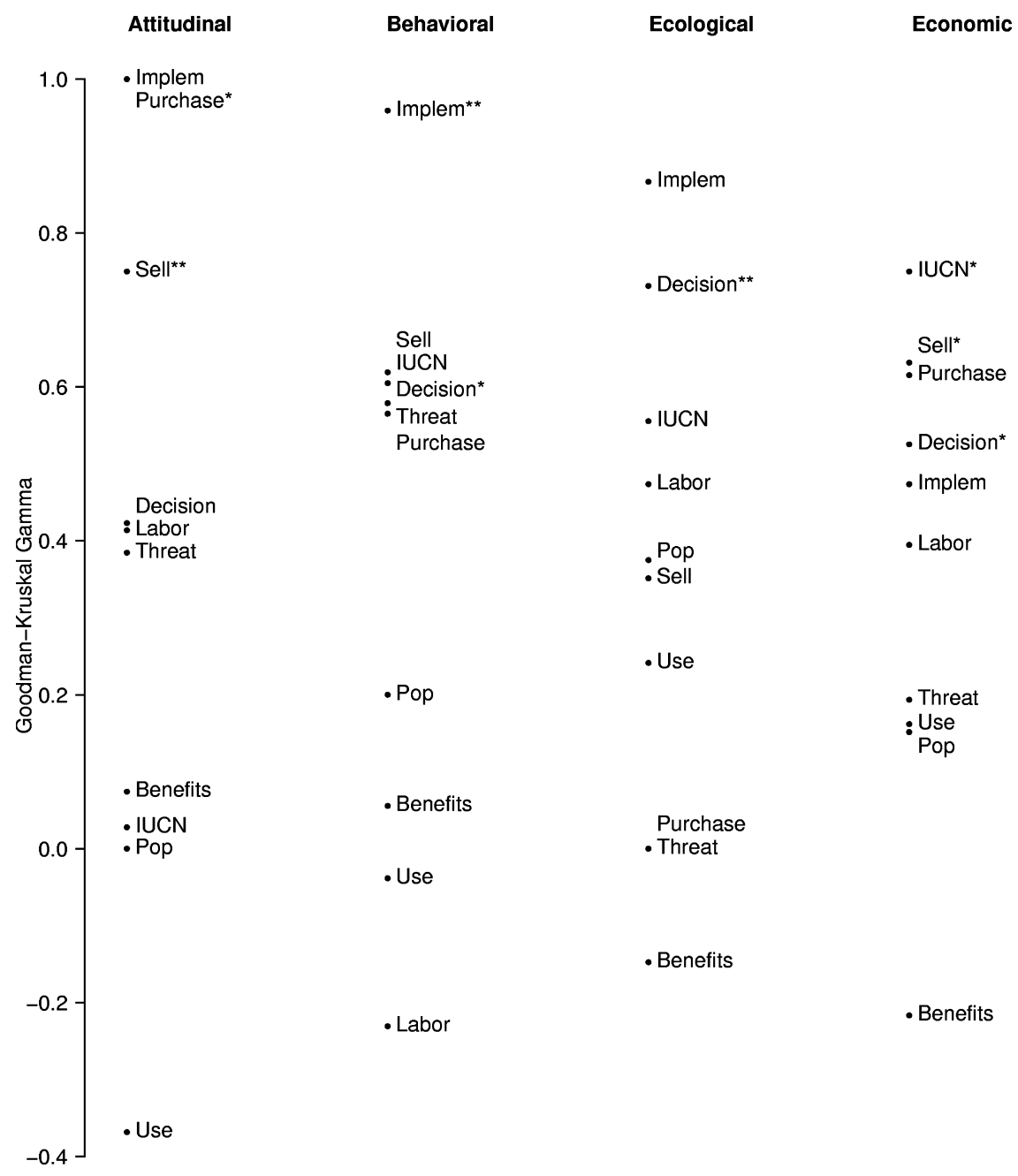

Figure 1. Goodman-Kruskal gamma statistics for contingency tables of predictors (in columns) and outcomes (column beadings). The value of gamma for the table is plotted along the y-axis. Gamma relatively close to 1 indicates $a$ positive association between the ordinal levels of predictor and outcome. Double asterisks indicate tables with q values in (0, 0.05), single asterisks q values in (0.05, 0.1). The eight tests having one or two asterisks are called significant. Significance levels are adjusted for the false discovery rate of the series of tests as described in the text (Implem denotes the variable implementation, and Pop denotes population). 


\section{Discussion}

The associations we observed consistently supported predictions stemming from the social-science framework that emphasizes utilization, decentralization, and market access as conservation strategies. These results suggest there are strengths to integrated conservation and development programs, at least under some circumstances, despite cogent critiques of some of the logic behind them (e.g., Robinson \& Redford 2004). We stress, however, that we view our results as provisional owing to the paucity of reliable data on project characteristics and outcomes. Because the majority of projects in our initial sample were inadequately monitored and assessed, the possibility remains that our final sample of 28 projects differs systematically with regard to characteristics and outcomes of "typical" ICDPs. Furthermore, the small size and incompleteness of some project records in our final sample make drawing conclusions a precarious task. The addition of even a few projects meeting our criteria would potentially change the results. These observations reflect the poor standards of monitoring and assessment-a shocking situation given the considerable budgets of many ICDPs. We discuss our findings as they pertain to the four original hypotheses.

\section{Utilization/Protection}

Greater access to natural resources within buffer zones or extractive reserves (as measured by IUCN status) was associated with economic success. This relationship provides some support for our hypothesis, although only economic outcomes are affected. The short time frame of the studies precludes us from determining whether economic success might presage other types of success in the future. For instance, we have no evidence that harvests are sustainable or that people permitted to enter buffer zones and harvest natural resources are more willing to limit their harvests or to respect fully protected zones. Such behavioral consequences are possible. For example, they might be responsible for the positive ecological outcomes observed in Costa Rica, where legal collection of turtle eggs through a permit system reduced illegal offtake, increased community protection of the resource, and appear to have led to increased turtle numbers (Campbell 1998). More generally, detecting links between utilization and conservation outcomes requires a detailed analysis of the extent to which utilization is permitted, its potential to generate income, its sustainability, the effectiveness of policing, and broader impacts of harvests on nontarget species. Although some studies have begun to unravel some of these dynamics at specific sites (Marcus 2001; Walpole \& Goodwin 2001; Struhsaker et al. 2005), data are not yet available to do this in a comparative context.
The hypothesis that most ecologists favor, that low protection and high utilization are associated with poor ecological outcomes, was not supported in our study. Although there is undeniable evidence that many natural resources cannot survive use (Alvard 1998; Robinson \& Bennett 2000; M.A.F., unpublished data), sustainable harvesting of some species (often plants and sometimes aquatic resources) can be a viable strategy in some cases, where institutions regulating sustainable management are strong, as in fisheries comanagement (Katon et al. 1999) or when population sources remain protected (Hill et al. 1997). Our results suggest that ICDPs are being set up at just such sites.

\section{Market Integration}

We predicted that higher levels of market integration would be associated with success in all four outcome measures. Projects in communities that were strongly affected by markets showed positive conservation attitudes. Furthermore, projects where communities sell heavily in local markets also tended to be successful economically. Although we have no measures of whether it is natural resources or other goods that are sold (or purchased) in markets, these findings are consistent with Godoy's (2001) suggestion that certain levels of market integration can potentially reduce indigenous impacts on game (see Godoy et al. 1995 for more tentative claims related to nontimber forest products).

We stress, however, that there is a great deal of evidence that commercialization, road access, and technology acquired through the market can jeopardize the sustainability of traditional resource exploitation patterns (e.g., Kaplan \& Kopishke 1992; Freese 1997; Robinson \& Bennett 2000). Ultimately, the impacts of economic development on local environments will depend on the nature of market access and the regenerative nature of the product(s) being marketed (Demmer et al. 2002). The potential conservation benefits contingent on local people obtaining access to substitute goods or alternative sources of income may be negated by the arrival of outsiders in search of natural resources, such as oil, timber, precious metals, or land for soybean production. We could not make such distinctions because they were not addressed in sufficient detail in the literature we used for coding.

\section{Decentralization}

The data suggest that greater community input into project implementation is associated with behavioral success, and that community involvement in day-to-day decision making is associated with behavioral, ecological, and economic success, supporting the claims of communitybased conservationists (e.g., Western \& Wright 1994) and allied approaches (Getz et al. 1999).

Despite the associations in the predicted direction, decentralization is no guarantee of success. Without solid 
community-level institutions for regulating common-pool resource use, decentralization may simply shift control to the elite in the community, doing little to solve the problem of resource exploitation (Wyckoff-Baird et al. 2000). Furthermore, the success of devolution depends critically on the nature of the institutions to which power is devolved (Borgerhoff Mulder \& Coppolillo 2005). Ultimately, when external funding dries up, the success of any project will depend on the ability of the local communities to manage their resources over the long term. Successful management is often determined by the effectiveness of community institutions (Agrawal 2002; Ribot 2004), which are frequently a function of our final variable, community homogeneity.

\section{Community Homogeneity}

Community homogeneity could not be properly addressed because of the high number of missing values in the one variable available to measure homogeneity. The prediction that cultural homogeneity should lead to success is also quite simplistic. Although homogeneity among group members is often listed as a characteristic necessary for community-level institutions (Wade 1988; Ostrom 1990; Baland \& Platteau 1996), some heterogeneity can be beneficial. The intuition here is that those with the most at stake may shoulder the costs of monitoring and enforcement and therefore contribute to the project's success (Olson 1965). Results from both modeling exercises and empirical investigations support this prediction (Agrawal \& Yadama 1997; Ruttan \& Borgerhoff Mulder 1999). Tremendous strides have been made in determining what community and environmental attributes contribute to successful resource regulation, but there is still uncertainty as to the role that cultural and economic homogeneity of the community plays.

\section{Data Quality}

Our lack of strong findings points to the urgent need for better, quantitative monitoring of conservation and development initiatives (Stem et al. 2003; Sutherland et al. 2004). Less than a quarter of the originally reviewed articles could be used in this study because of a lack of monitoring. Of the 28 projects we did use, only 8 monitored all four aspects of success, and 7 of the remaining 20 monitored only two aspects. In addition, many of the project assessments lacked rigor. Only one project quantitatively monitored all four aspects of success, and only two projects quantitatively monitored three of the aspects (Campbell 1998; Marcus 2001). Ten projects had no quantitative monitoring, instead relying on qualitative findings that were, at best, only suggestive of success or failure. In addition, measures of ecological success (or limited success) were not ideal. Examples of ecological assessment in our study sample ranged from quantified measures of declining rates in deforestation (Community Initiative Program [CIP], Brazil) or linear regressions of the percentage of land a household has in forest cover (Corcovado National Park/Pierdras Blancas National Park, Costa Rica) to qualitative observations regarding the decision to set aside land for a mahogany reserve (CI-Brasil Pinkaiti Research Station Project), success in managing grass collection inside a reserve (Royal Chitwan National Park, Nepal), or an effective tree-planting scheme (KilumIjim Forest, Cameroon).

\section{Comparisons with Other Studies}

Our results pertaining to the decentralization hypothesis are largely consistent with those of Salafsky et al. (2001), who found that the extent to which community members are involved in the management and design of a project was particularly important for ecological success. Our results are inconsistent with the demonstration of the success of protectionism by Bruner et al. (2001), but are not strictly comparable because we evaluated a suite of alternative hypotheses and outcome measures, whereas Bruner et al. addressed only protectionism and found that ecological success was associated with protectionism, but we found no such effect. Rather we found significant behavioral and economic success in the absence of protectionism. Struhsaker et al. (2005) found that ecological success was associated with many predictive variables (such as effective law enforcement, low population level, and large reserve size) but not with employment benefits, multiple forms of extension (such as conservation education and conservation clubs), or with the presence of integrated conservation and development initiatives in the area, findings that are again inconsistent with our results.

There are many reasons why our results might differ. First Struhsaker et al. (2005) look only at tropical forest ecosystems, and only in Africa. Most likely, different strategies will be suited to different kinds of conservation challenges. Second, it remains a strong possibility that ICDPs and other kinds of extension services are established precisely in those areas where the most acute conservation challenges exist. This would account for the association between poor ecological outcomes and ICDPs in the study by Struhsaker et al. (2005). Our study was immune to this particular problem because only ICDP sites were sampled. Third, their findings are inconsistent with evidence from Tanzania showing (through multiple logistic regression) that differences among individuals in their attitudes to Katavi National Park are largely a function of the perception of park outreach activities (Holmes 2003). This highlights the fact that although overall outreach may not be associated with success (in a between-project comparison such as in Struhsaker et al.), within-project variability in perception of outreach services can have major conservation impacts. This distinction must be kept clear when considering management implications of apparently contradictory studies. Fourth, Struhsaker et al. (2005) rely on questionnaires with managers and 
scientists and personal observations, whereas we relied on published peer-reviewed reports. Which source of data is less problematic is an open question. Both are clearly fraught with potential bias, although the strategy of Struhsaker et al. provides a much cleaner data set with fewer missing values, thereby affording greater statistical flexibility. Without independent measures of the various biases entailed in both strategies, it seems wise to pursue both approaches.

\section{Future Directions}

Clearly we concur with Sutherland et al. (2004) that a comprehensive remedy lies in concentrating more funds and study into collecting relevant monitoring data. High priority should be given to longitudinal rather than crosssectional studies in evaluating the success of any strategy because of the problem of endogeneity (such as ICDPs being set up in troubled areas). To facilitate comparative analyses in the future, primary researchers and evaluation teams need to be clear about the specific problem that the project is designed to address and the goals of the project in each of the four outcome areas.

We also emphasize the importance of including multiple measures of success. Rigorously collected data that cover only one or two measures of success have limited analytical value because conservation and development projects almost inevitably have ecological, economic, and social consequences. Without measures of success that span these distinct dimensions, the effectiveness of the conservation and development paradigm cannot be determined. We originally intended to use only projects with data on all four dimensions, with the aim of analyzing the interdependencies among different measures of success. In our final sample, there was consistency among outcomes in $75 \%, 31 \%$, and $100 \%$ of projects with four, three, and two outcome measures, respectively. Until a more statistically powerful study of the consistencies (and inconsistencies) among outcomes can be made, conservationists face a situation in which a particular project, for example an extractive reserve, may be judged a success by an economist based on increased income for local inhabitants and a failure by an ecologist and an anthropologist based on, respectively, a critical population decline within the ecosystem and an absence of changed community values regarding conservation. Insofar as the conservation and development paradigm is founded on the assumption that human and ecological well-being are inextricably linked, proper support for this paradigm will need to demonstrate empirically such an interdependence of measures of success.

\section{Acknowledgments}

Thanks to T. Caro, M. Lubell, L. Naughton-Treves, T. Young, and our lab group members for extremely helpful comments and suggestions on the manuscript and to the University of California at Davis for Faculty Research Grants to M.B.M.

\section{Supplementary Material}

The following supplementary material is available as part of the on-line article from http://www.blackwellsynergy.com:

Appendix S1. A list of conservation and development projects in the final sample (including project name, location, and source).

Appendices S2-S8. The final coded data set, scripts in the $\mathrm{R}$ statistical language, and brief directions for running the scripts.

\section{Literature Cited}

Abbot, J. I. O., D. H. L. Thomas, A. A. Gardner, S. E. Neba, and M. W. Khen. 2001. Understanding the links between conservation and development in the Bamenda highlands, Cameroon. World Development 29:1115-1136

Adams, W., and D. Hulme. 2001. Conservation and community: changing narratives, policies and practices in African conservation. Pages 9-23 in D. Hulme and M. Murphree, editors. African wildlife and livelihoods: the promise and performance of community conservation. James Currey, Oxford, United Kingdom.

Agrawal, A. 2002. Common resources and institutional sustainability. Pages 41-85 in E. Ostrom, T. Dietz, N. Dolsak, P. Stern, S. Stronich, and E. Weber, editors. The drama of the commons. National Academy Press, Washington, D.C.

Agrawal, A., and G. N. Yadama. 1997. How do local institutions mediate market and population pressures on resources? Forest panchayats in Kumaon, India. Development and Change 28:435-465.

Agresti, A. 1990. Categorical data analysis. John Wiley and Sons, New York.

Alvard, M. S. 1998. Evolutionary ecology and resource conservation. Evolutionary Anthropology 7:62-74.

Baland, J., and J. Platteau. 1996. Halting degradation of natural resources: is there a role for rural communities? Oxford University Press, Oxford, United Kingdom.

Balmford, A., and T. Whitten. 2003. Who should pay for tropical conservation, and how could the costs be met? Oryx 37:238-250.

Barrett, C. B., and P. Arcese. 1995. Are integrated conservationdevelopment projects (Icdps) sustainable-on the conservation of large mammals in Sub-Saharan Africa. World Development 23:10731084 .

Barrow, E., and M. Murphree. 2001. Community conservation: from concept to practice. Pages 22-37 in D. Hulme and M. Murphree, editors. African wildlife and livelihoods: the promise and performance of community conservation. James Currey, Oxford, United Kingdom.

Benjamini, Y., and Y. Hochberg. 1995. Controlling the false discovery rate-a practical and powerful approach to multiple testing. Journal of the Royal Statistical Society Series B-Methodological 57:289300

Berkes, F., P. J. George, and R. J. Preston. 1991. Co-management: the evolution in theory and practice of the joint administration of living resources. Alternatives 18:12-18.

Borgerhoff Mulder, M., and P. Coppolillo. 2005. Conservation: linking ecology, economics, and culture. Princeton University Press, Princeton, New Jersey.

Brandon, K. 1997. Policy and practical considerations in land-use strategies for biodiversity conservation. Pages 90-114 in R. A. Kramer, C. van Schaik, and J. Johnson, editors. Last stand: protected areas and 
the defense of tropical biodiversity. Oxford University Press, New York.

Browder, J. O. 1992. The limits of extractivism-tropical forest strategies beyond extractive reserves. BioScience 42:174-183.

Brown, K. 2002. Innovations for conservation and development. The Geographical Journal 168:6-17.

Bruner, A. G., R. E. Gullison, R. E. Rice, and G. A. B. da Fonseca. 2001. Effectiveness of parks in protecting tropical biodiversity. Science 291:125-128.

Campbell, L. M. 1998. Use them or lose them? Conservation and the consumptive use of marine turtle eggs at Ostional, Costa Rica. Environmental Conservation 25:305-319.

Caro, T. M., N. Pelkey, M. Borner, K. L. I. Campbell, B. L. Woodworth, B. P. Farm, J. Ole Kuwai, S. A. Huish, and E. L. M. Severre. 1998. Consequences of different forms of conservation for large mammals in Tanzania: preliminary analyses. African Journal of Ecology 36:303320.

Cohen, A., and H. B. Sackrowitz. 1992. An evaluation of some tests of trend in contingency-tables. Journal of the American Statistical Association 87:470-475.

Demmer, J., et al. 2002. Do levels of income explain differences in game abundance? An empirical test in two Honduran villages. Biodiversity and Conservation 11:1845-1868.

Fearnside, P. M. 1989. Extractive reserves in Brazilian Amazonia. BioScience 39:387-393.

Ferraro, P. J., and A. Kiss. 2002. Ecology-direct payments to conserve biodiversity. Science 298:1718-1719.

Flintan, F. 2000. Investigating the imbalance of gender and ICDPs-past and present research. A paper presented at the International Seminar on Integrated Conservation and Development: contradiction of terms? CARE-Denmark, Copenhagen, Denmark.

Freese, C. H., editor. 1997. Harvesting wild species: implications for biodiversity conservation. Johns Hopkins University Press, Baltimore, Maryland.

Getz, W. M., L. Fortmann, D. Cumming, J. du Toit, J. Hilty, R. Martin, M. Murphree, N. Owen-Smith, A. M. Starfield, and M. I. Westphal. 1999. Conservation-sustaining natural and human capital: villagers and scientists. Science 283:1855-1856.

Godoy, R., N. Brokaw, and D. Wilkie. 1995. The effect of income on the extraction of non-timber tropical forest products-model, hypotheses, and preliminary findings from the Sumu Indians of Nicaragua. Human Ecology 23:29-52.

Godoy, R. A. 2001. Indians, markets, and rainforests. Columbia University Press, New York.

Goodman, L. A., and W. H. Kruskal. 1954. Measures of association for cross classifications. Journal of the American Statistical Association 49:732-764.

Hill, K., J. Padwe, C. Bejyvagi, A. Bepurangi, F. Jakugi, R. Tykuarangi, and T. Tykuarangi. 1997. Impact of hunting on large vertebrates in the Mbaracayu reserve, Paraguay. Conservation Biology 11:13391353.

Holmes, C. M. 2003. The influence of protected area outreach on conservation attitudes and resource use patterns: a case study from western Tanzania. Oryx 37:305-315.

Honey, M. 1999. Ecotourism and sustainable development: who owns paradise? Island Press, Washington, D.C.

Hulme, D., and M. Murphree. 1999. Communities, wildlife, and the "new conservation" in Africa. Journal of International Development 11:277-285.

Hulme, D., and M. Murphree, editors. 2001. African wildlife and African livelihoods: the promise and performance of community conservation. James Currey, Oxford, United Kingdom.

Jacobson, S. K., and M. D. McDuff. 1998. Conservation education. Pages 237-255 in W. J. Sutherland, editor. Conservation science and action. Blackwell Science, Oxford, United Kingdom.
Kaplan, H., and K. Kopishke. 1992. Resource use, traditional technology, and change among native peoples of lowland South America. Pages 83-107 in K. H. Redford, and C. Padoch, editors. Conservation of neotropical forests. Columbia University Press, New York.

Katon, B. M., R. S. Pomeroy, L. R. Garces, and A. M. Salamanca. 1999. Fisheries management of San Salvador Island, Philippines: a shared responsibility. Society \& Natural Resources 12:777-795.

Lindsay, W. K. 1987. Integrating parks and pastoralists: some lessons from Amboselli. Pages 149-167 in D. Anderson and R. Grove, editors. Conservation in Africa: people, politics, and practice. Cambridge University Press, Cambridge, United Kingdom.

McShane, T. O., and M. P. Wells. 2004. Getting biodiversity projects to work: towards a more effective conservation and development. Columbia University Press, New York.

Marcus, R. R. 2001. Seeing the forest for the trees: integrated conservation and development projects and local perceptions of conservation in Madagascar. Human Ecology 29:381-397.

Muller, S. 2003. Toward decolonisation of Australia's protected area management: the Nantawarrina indigenous protected area experience. Australian Geographical Studies 41:29-43.

Murphree, M. 1994. The role of institutions in community-based conservation. Pages 403-427 in D. Western and R. M. Wright, editors. Natural connections: perspectives on community-based conservation. Island Press, Washington, D.C.

Naughton-Treves, L., M. Buck, and K. Brandon. 2005. The role of protected areas in conserving biodiversity and sustaining local livelihoods. Annual Review of Environment and Resources 30:219252.

Oates, J. F. 1999. Myth and reality in the rain forest: how conservation strategies are failing in West Africa. University of California Press, Berkeley.

Olson, M. 1965. The logic of collective action: public goods and the theory of groups. Harvard University Press, Cambridge, Massachusetts.

Ostrom, E. 1990. Governing the commons: the evolution of institutions for collective action. Cambridge University Press, Cambridge, United Kingdom.

R Development Core Team. 2004. R: a language and environment for statistical computing. R Foundation for Statistical Computing, Vienna.

Redford, K. H. 1992. The empty forest. BioScience 42:412-422.

Ribot, J. C. 2004. Waiting for democracy: the politics of choice in natural resource decentralization. World Resources Institute, Washington, D.C.

Roback, P. J., and R. A. Askins. 2005. Judicious use of multiple hypothesis tests. Conservation Biology 19:261-267.

Robinson, J. G., and E. L. Bennett, editors. 2000. Hunting for sustainability in tropical forests. Columbia University Press, New York.

Robinson, J. G., and K. H. Redford. 2004. Jack of all trades, master of none: inherent contradictions among ICDP approaches. Pages 1034 in T. McShane and M. Wells, editors. Getting biodiversity projects to work. Columbia University Press, New York.

Ruttan, L. M., and M. Borgerhoff Mulder. 1999. Are east African pastoralists truly conservationists? Current Anthropology 40:621-652.

Salafsky, N., and E. Wollenberg. 2000. Linking livelihoods and conservation: a conceptual framework and scale for assessing the integration of human needs and biodiversity. World Development 28:14211438.

Salafsky, N., H. Cauley, G. Balachander, B. Cordes, J. Parks, C. Margoluis, S. Bhatt, C. Encarnacion, D. Russell, and R. Margoluis. 2001. A systematic test of an enterprise strategy for community-based biodiversity conservation. Conservation Biology 15:1585-1595.

Saterson, K. A., N. L. Christensen, R. B. Jackson, R. A. Kramer, S. L. Pimm, M. D. Smith, and J. B. Wiener. 2004. Disconnects in evaluating the relative effectiveness of conservation strategies. Conservation Biology 18:597-599.

Schwartzman, S., A. Moreira, and D. Nepstad. 2000a. Rethinking tropical 
forest conservation: perils in parks. Conservation Biology 14:13511357.

Schwartzman, S., D. Nepstad, and A. Moreira. 2000b. Arguing tropical forest conservation: people versus parks. Conservation Biology 14:1370-1374.

Stem, C. J., J. P. Lassoie, D. R. Lee, D. D. Deshler, and J. W. Schelhas. 2003. Community participation in ecotourism benefits: the link to conservation practices and perspectives. Society \& Natural Resources 16:387-413.

Storey, J. D. 2002. A direct approach to false discovery rates. Journal of the Royal Statistical Society Series B-Statistical Methodology 64:479498.

Struhsaker, T. T., P. J. Struhsaker, and K. S. Siex. 2005. Conserving Africa's rain forests: problems in protected areas and possible solutions. Biological Conservation 123:45-54.

Sutherland, W. J., A. S. Pullin, P. M. Dolman, and T. M. Knight. 2004. The need for evidence-based conservation. Trends in Ecology \& Evolution 19:305-308.

Wade, R. 1988. Village republics: economic conditions for collective action in South India. Cambridge University Press, New York.
Walpole, M. J., and H. J. Goodwin. 2001. Local attitudes towards conservation and tourism around Komodo national park, Indonesia. Environmental Conservation 28:160-166.

Wells, M., K. Brandon, and L. Hannah. 1992. Parks and people: linking protected area management with local communities. World Bank, Washington, D.C.

Wells, M., S. Guggenheim, A. Khan, W. Wardojo, and P. Jepson. 1999. Investing in biodiversity: a review of Indonesia's integrated conservation and development projects. World Bank, Washington, D.C.

Western, D. 1994. Ecosystem conservation and rural development: the case of Amboseli. Pages 15-52 in D. Western, R. M. Wright, and S. C. Strum, editors. Natural connections: perspectives in communitybased conservation. Island Press, Washington, D.C.

Western, D., and M. Wright, editors. 1994. Natural Connections: Perspectives in community-based conservation. Island Press, Washington, D.C.

Wyckoff-Baird, B., A. Klaus, C. Christen, and M. Keck. 2000. Shifting the power: decentralization and biodiversity conservation. Biodiversity Support Program, Washington, D.C.

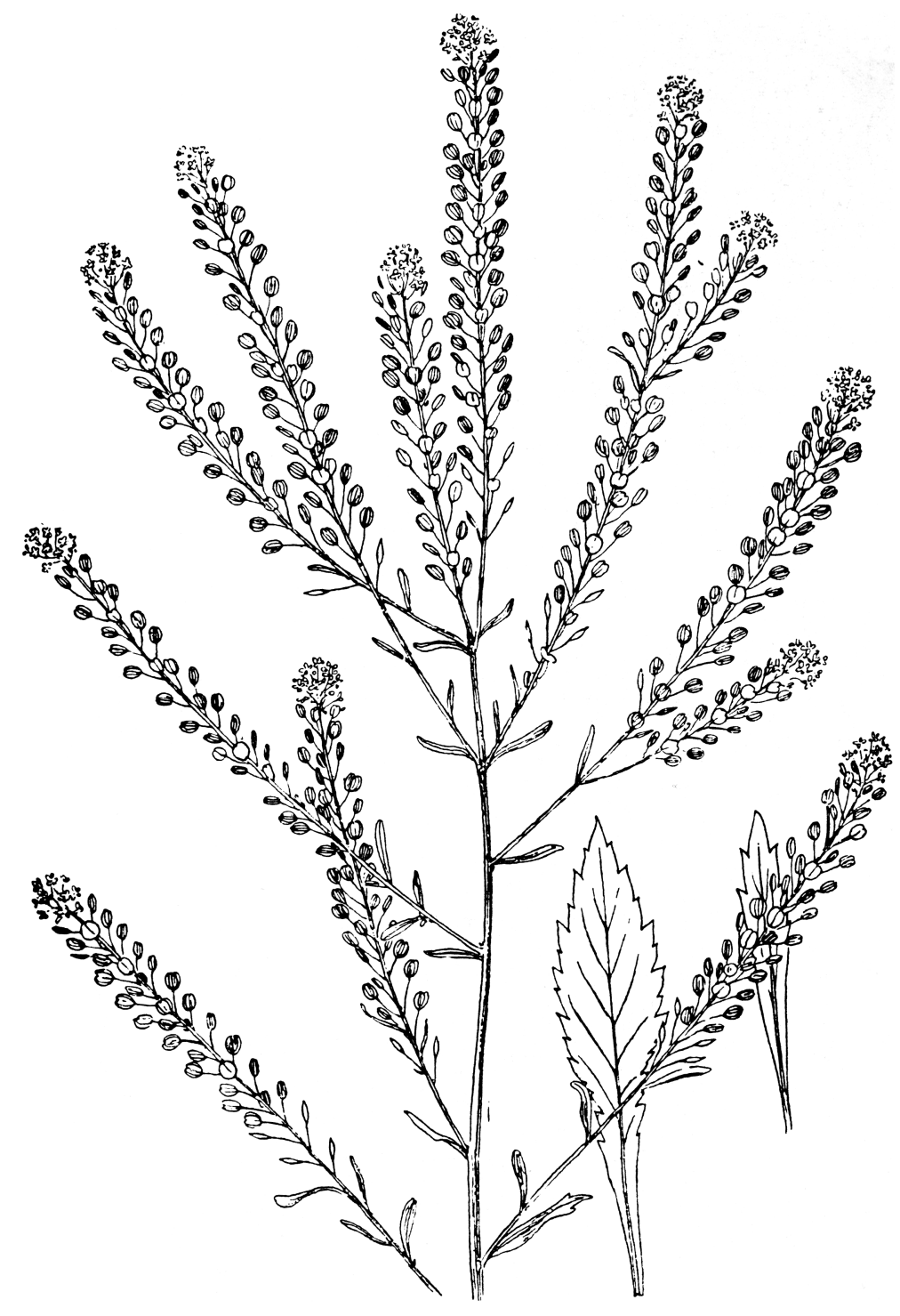

